\title{
Parental safety concerns and active school commute: correlates across multiple domains in the home-to-school journey
}

Abiodun O Oluyomi ${ }^{1 *}$, Chanam Lee ${ }^{2}$, Eileen Nehme ${ }^{1}$, Diane Dowdy ${ }^{3}$, Marcia G Ory ${ }^{3}$ and Deanna M Hoelscher ${ }^{1}$

\begin{abstract}
Background: Empirical evidence of the relationship between safety concerns and walking to school (WTS) is growing. However, current research offers limited understanding of the multiple domains of parental safety concerns and the specific mechanisms through which parents articulate safety concerns about WTS. A more detailed understanding is needed to inform environmental and policy interventions. This study examined the relationships between both traffic safety and personal safety concerns and WTS in the U.S.
\end{abstract}

Methods: This cross-sectional analysis examined data from the Texas Childhood Obesity Prevention Policy Evaluation (T-COPPE) project, an evaluation of state-wide obesity prevention policy interventions. All study data were from the survey $(n=830)$ of parents with 4th grade students attending 81 elementary schools across Texas, and living within two miles from their children's schools. Traffic safety and personal safety concerns were captured for the home neighborhood, en-route to school, and school environments. Binary logistic regression analysis was used to assess the odds of WTS controlling for significant covariates.

Results: Overall, $18 \%$ of parents reported that their child walked to school on most days of the week. For traffic safety, students were more likely to walk to school if their parent reported favorable perceptions about the following items in the home neighborhood environment: higher sidewalk availability, well maintained sidewalks and safe road crossings. For the route to school, the odds of WTS were higher for those who reported "no problem" with each one of the following: traffic speed, amount of traffic, sidewalks/pathways, intersection/crossing safety, and crossing guards, when compared to those that reported "always a problem". For personal safety in the en-route to school environment, the odds of WTS were lower when parents reported concerns about: stray or dangerous animals and availability of others with whom to walk.

Conclusions: Findings offered insights into the specific issues that drive safety concerns for elementary school children's WTS behaviors. The observed associations between more favorable perceptions of safety and WTS provide further justification for practical intervention strategies to reduce WTS barriers that can potentially bring long-term physical activity and health benefits to school-aged children.

Keywords: Active commuting to school, Walking to school, Child pedestrian, Traffic safety, Personal safety, Crime safety, Pedestrian safety, Physical activity, Environmental perception, Safe routes to school

\footnotetext{
* Correspondence: Abiodun.O.Oluyomi@uth.tmc.edu

${ }^{1}$ The Michael \& Susan Dell Center for Healthy Living, UT School of Public Health, Austin Regional Campus, The University of Texas Health Science Center at Houston, 1616 Guadalupe, Suite 6.300, Austin, TX 78701, USA Full list of author information is available at the end of the article
} 


\section{Background}

The emerging attention focused on walking to school (WTS), particularly in industrialized countries, is grounded in the recognition of the importance of physical activity among children who are adopting increasingly sedentary lifestyles [1,2]. Physical activity has both a positive, direct effect on children's health and an indirect effect through its role in healthy weight maintenance or weight loss among the overweight $[3,4]$. The effect of physical activity on adiposity makes it an essential component in combating the childhood obesity epidemic, and studies have documented a positive relationship between WTS and other forms of physical activity. Recent studies have shown that elementary school students who walk/bike to school (1) may obtain more daily physical activity than those using motorized commuting modes [5-8]; (2) are more likely to engage in physical activity outside school $[6,9,10]$; and (3) are more likely to walk/bike to other non-school destinations [11].

Despite its potential health benefits, rates of active commuting to school (e.g. walking and bicycling) have plummeted over the last four decades in the U.S. In 2009, only $12.7 \%$ of elementary and middle school students walked or biked to school compared with $47.7 \%$ in 1969 [12]. Several reasons for this sharp drop in active commuting to school (ACS) have been identified by parents with schoolaged children (5-18 years old), including distance (62\%), traffic-related danger (30.4\%), weather (18.6\%), crime (11.7\%), and school policy (6.0\%) [13]. For WTS, two of the most frequently reported barriers are long distance [14-18] and safety concerns [19-21]. Addressing the distance barrier, while being the most influential factor predicting the school travel model choice, is difficult as it requires multi-faceted environmental interventions involving policy changes in land use, school siting, attendance zone, etc. [22]. In comparison, environmental changes to alleviate safety barriers to WTS may be more readily implementable.

While safety concerns are hypothesized barriers to WTS, there is clearly the need for more focused empirical inquiries into the potential relationship between these two phenomena because current research offers little in terms of exploring/explaining the mechanisms through which safety concerns might impact active transport [23,24]. Generally, safety concerns have been investigated in terms of road safety (traffic- or pedestrian-related safety concerns) and personal safety (crime- or predator-related safety concerns). Better understanding of the relationships between multiple domains of safety concerns and WTS can contribute to the development of practical intervention strategies to reduce barriers to WTS, which may lead to increases in physical activity and long-term health benefits to school-aged children.

To contribute to the growing yet limited body of literature on safety and WTS, we examined the relationships between WTS and specific measures of road and personal safety measures in a sample of U.S. schoolchildren who were selected from elementary schools across Texas. We also examined the relationships between selected covariates and walking, in order to obtain insights into the relations between these covariates in our population, as well as to adjust for the effects of the socio-demographic covariates in the potential relationships between safety concerns and WTS.

\section{Methods \\ Design}

This was a cross-sectional study using the baseline parental survey data from the Texas Childhood Obesity Prevention Policy Evaluation (T-COPPE) project. T-COPPE is an ongoing 5-year project that evaluates state-level implementation of two key national obesity prevention policies in Texas: the Safe Routes to School (SRTS) program and the Women, Infants and Children (WIC) revised food package. T-COPPE aims to: (1) inform decision makers about the effectiveness of these policies, and (2) assist local, state, and national policymakers to identify policies for promoting children's healthy eating and increased physical activity. At baseline (2009), T-COPPE recruited a total of 81 schools to participate in the project from 58 cities in 43 counties where the Texas Department of Transportation had approved SRTS projects as part of SAFETEALU (Safe Accountable Flexible Efficient Transportation Equity Act: A Legacy for Users). All study protocols and instruments were approved by The University of Texas Health Science Center at Houston Institutional Review Board.

\section{Sample}

All 4th grade students and their parents ( $n=6,500$ pairs) from the approved schools were invited to complete TCOPPE baseline surveys. A total of 2,053 (31.6\%) parent surveys and 3,315 (51\%) student surveys were returned, out of which were 1,635 parent-student dyads. About eighty percent $(n=1,305)$ of the dyads' home addresses were successfully geocoded using a geographic information system (GIS) technology (ESRI, ArcGIS 10.0). The inclusion criterion for the current analysis was that the residential address of the participant must be within walkable distance to their school, as defined by living within a 2-mile $(3.2 \mathrm{~km})$ distance from their school. This distance was selected since, according to the State of Texas, a student must live two miles or more from his/her assigned school to be eligible for free regular education school bus transportation [25]. The two-mile distance was determined based on the objectively-measured, shortest network distance from home to school, using GIS. Out of the 857 living in the two-mile distance to school, the mode choice to school was not reported for 27 , leaving 830 participants for analysis. 


\section{Measures}

The parents of students who participated in the T-COPPE study received a packet that consisted of the consent form and parent survey prior to the student survey administration, which occurred at the child's school. Parents returned the consent and completed survey to their child's teacher in a sealed envelope. For the outcome of interest, walking to school (WTS), we used the relevant question from the National Safe Route To School Survey. Children were classified as walkers if their parents answered "walking" to the question - "On most days how does your 4th grade child arrive at school and leave after school?" [26]. Since WTS has been shown to vary significantly by certain individual- and societal-level characteristics [27-29], we assessed selected covariates in terms of five themes: socio-demographic status, acculturation, medical condition, school policy, and social capital (civic engagement and social integration). The primary exposures of interest for the current study were perceived traffic safety concerns and perceived personal safety concerns, examined across three environmental domains in the home-to-school journey - the home neighborhood environment, the en-route to school environment, and the school environment.

All data analyzed in the current study were retrieved from the T-COPPE survey. Questions in the T-COPPE survey were adapted from several surveys, including: the National Center for Safe Routes To School Parent Survey [26]; the School Physical Activity and Nutrition (SPAN) parent survey [30]; the Urban Hispanic Perceptions of Environment and Activity Among Kids (UH-PEAK) [31]; the Neighborhood Environment Walkability Survey (NEWS) [32,33]; and the TV reduction intervention study (En Vivo) [34]. Additional questions were adapted from specific relevant published reports $[35,36]$. Questions used in the current study, their response types, and their sources are listed in Table 1.

\section{Analysis}

All statistical analyses were conducted in SPSS version 19. We assessed the relationships between potential covariates and WTS with chi-square tests. For each theme, multiple $(x)$ comparisons were performed to assess the association between each constituent variable in the theme and WTS. Therefore, the test specific Bonferroni alpha level significance adjustment for the chi-square tests of $p \leq(0.05 / x)$ was used to conserve the family-wise error rate of 0.05 . For example, the alpha level of significance was $\mathrm{p} \leq 0.01$ for the socio-demographic factors, since five different comparisons were performed. For exploratory purposes, we checked for correlations among the selected variables for each theme (demography/SES evaluated separately from school policy variables), using Spearman's Rho tests (p). We also examined multicollinearity using the variance inflation factor (VIF).
Second, bivariate analyses of each exposure variable (by environment; i.e. home neighborhood, en-route, and school environment) were conducted with the dichotomous outcome measure of WTS. Logistic regression models were used to determine unadjusted odds ratios. Next, we performed a series of multivariable regression models, controlling for certain socio-demographic/SES factors that we chose as potential confounding variables; i.e. student's ethnicity, any type of public assistance (family), car ownership (family). These were chosen based on the prior knowledge of their relationships with the outcome (WTS) and neighborhood of residence - which is expected to inform neighborhood perceptions. The Hosmer-Lemeshow goodness-of-fit statistic was used to assess model fit. Models that provided a good fit to the data had a small test statistic and a large $\mathrm{p}$ value ( $p>$ established cutoff of 0.05).

\section{Results}

\section{Population characteristics and relationship with walking} to school

Overall, $18.7 \%$ of parents reported WTS as their child's commute mode choice while only $1.8 \%$ biked. The remaining $79.5 \%$ used a combination of transit, carpooling, and family vehicle (Table not shown). Table 2 presents data on sample characteristics and their relationships with WTS. Boys and girls were equally represented in the study, with majority being Hispanics. Almost one-third of the families received public assistance, most parents reported high school or General Education Development Certificate (GED) as their highest level of education, and almost every family had a vehicle. The majority of the parents were born in the US, most of them thought and spoke in the English language, and a very small proportion of the students were born outside the US. In the exploratory analyses of study characteristics as covariates (Table 2), the following groups were more likely to have walked to school when compared to their counterparts, at the Bonferroni adjustment alpha level $-p \leq(0.05 / x)$ - families that received any public assistance; students from families that owned no/one vehicle; students whose teachers encouraged active school commuting; and students whose parents reported that child's school encouraged active commuting. Other covariates that showed significance at $\mathrm{p} \leq 0.05$ included: parent voting in election, attending civic meetings, or volunteering at child's school.

\section{Relationships among covariates}

Generally, correlations among significant covariates were low across the themes that we examined (Table not shown). For socio-demographic theme, three correlation pairs (including ethnicity) were between $\rho=0.109$ and 0.289 (all $p<0.01$ ). Two of the three correlation pairs for 
Table 1 Variables, the response types used, and the sources of the questions used

Variables

\section{Traffic safety}

Home neighborhood environment

$\begin{array}{ll}\text { (1) } & \text { Availability and quality of sidewalks } \\ \text { (3) } & \text { Safe road crossings } \\ & \text { Observance of other people walking or bicycling }\end{array}$

Rating scale (Likert)

En-route environment
(4)
(5)
(6)
Availability of sidewalks/pathways
Safety at intersections/crossings

School environment
(7) Availability and quality of sidewalks
(8) Availability and quality of bike lanes/paths and bike racks
(9) Trees along the streets; and safe road crossings.

\section{Personal Safety}

Home neighborhood environment

(10) Safety of their child to walk or bike
(11) $\quad$ Personal sense of fear when walking outside alone after dark

En-route environment

Availability of adults or other children to walk with

Violence or crime (e.g. Bullying/gangs)

And stray or dangerous animals

School environment

Attractive buildings or natural things to see

Abandoned houses or vacant lots

Condoms and drug-related paraphernalia

Well-maintained homes/apartments and gardens

Other people who walk/bike

\section{Potential Covariates}

Socio-demographic status

(20)

(21)

(22)

Acculturation

Medical condition
Government public assistance

Respondent's highest level of education

The family car-ownership status

The language parents spoke in "most of the time"

The language parents thought in "most of the time"

Parents reported if child's grandparents were born in the US

Parents reported if they were born in the US

Parents reported if their children were born in the US

Medical conditions that limit physical activity for parents

Medical conditions that limit physical activity for child

Child has asthma

If asthma, is it well controlled
Rating scale (Likert)

[31]

Rating scale (Likert)

Rating scale (Likert)

Rating scale (Likert)

Rating scale (Likert)

Rating scale (Likert)

Rating scale (Likert)

Rating scale (Likert)

Rating scale (Likert)

Rating scale (Likert)

Rating scale (Likert)

Rating scale (Likert)

[31]

Rating scale (Likert)

[31]

Rating scale (Likert)

Rating scale (Likert)

Rating scale (Likert)

Binary response

[38,39]

Multiple options

[38,39]

Multiple options

Multiple options

[41]

Multiple options

Binary response

[41]

Binary response

Binary response

Binary response

Binary response

Binary response

Binary response 


\section{Table 1 Variables, the response types used, and the sources of the questions used (Continued)}

School policy

Social capital: civic engagement

Teachers encouraged students to walk/bike to school

Schools had a walking school bus program

Child's school encouraged or discouraged walk/bike to school

Voted in an election (local, state, or national)

Written or called a government official about community issue

Attended a meeting of any government body

Volunteered at the child's school

Volunteered for any community organization

Social capital: social integration

People in my community work together to resolve problems

People in my community are only out for themselves

A small group of people has all the power in my community

I feel like an outsider in my community

There is nothing I can do to solve problems in my community
Binary response

Binary response

Rating scale (Likert)

Binary response

$[35,36]$

Binary response

$[35,36]$

Binary response

$[35,36]$

Binary response

$[35,36]$

Binary response

$[35,36]$

Rating scale (Likert)

[36]

Rating scale (Likert)

[36]

Rating scale (Likert)

[36]

Rating scale (Likert)

[36]

Rating scale (Likert) school policy were significant $(p<0.05)$, with highest $\rho=$ 0.163 , while all three correlation pairs for civic engagement were significant $(p<0.05)$, with highest $\rho=0.272$. Secondary assessment of possible multicollinearity using the VIF supported lack of significant correlations among selected covariates; the highest VIF score across all the selected variables was 1.11. Based on the observed $\rho$ values for demography and SES (potential confounders), multivariable analyses that include these covariates would not be affected by multicollinearity.

\section{Unadjusted and adjusted relationships between perceived road safety and walking to school}

In the home neighborhood environment, bivariate analysis showed that three out of the four items in this domain were statistically significant. The likelihood (odds ratio) of walking was greater for students whose parents reported that there were sidewalks on most of their neighborhood streets than for those who reported no sidewalks. Similarly, there was increased likelihood of walking among two groups of students when compared to their counterparts: those whose parents reported that neighborhood sidewalks were well maintained, and that there were safe road crossings in their neighborhood. In the en-route environment, all five items examined showed significant associations with WTS. These were: speed of traffic along route to school; amount of traffic along route to school; intersection safety; crossing problems; and availability of crossing guards. In the school environment, WTS was higher when parents reported sufficient sidewalks near their child's school vs. no sidewalks, as well as reporting availability of safe crossings vs. no safe crossings. Details presented in Table 3.
Each safety variable from the unadjusted bivariate analyses was included in a multivariable logistic model that included the selected confounders - student ethnicity, public assistance, and car ownership. The results are displayed in Table 3. For home neighborhood environments, the likelihood of WTS remained higher with higher sidewalk availability, well maintained sidewalks, and safe road crossings. Similarly, all items in the en-route environments retained significant relationships with WTS after adjustment. For the school environment, sidewalk on streets, bike lanes/paths, and safe road crossings maintained associations with WTS in the adjusted analyses. Sidewalk maintenance near school and trees along streets near school showed significant associations with WTS after adjusting for confounders. The Hosmer-Lemeshow (H-L) test indicated a good fit for each one of these multivariable models (data not shown).

\section{Unadjusted and adjusted relationships between perceived personal safety and walking to school}

In the home neighborhood environment, bivariate analysis showed that one out of the four items in this domain was associated with WTS; parents who reported that it was safe for their child to walk or bike in the neighborhood also reported higher WTS when compared to their counterparts. In the en-route environment, children were less likely to report WTS if their parents reported some measure of concern on the following issues: having other adults or children to walk with; violence or crime problems; and stray or dangerous animals. None of the constituent variables for personal safety in the school environment showed significant association with WTS. More details are given in Table 4. 
Table 2 Population characteristics and their relationships with walking to school

\begin{tabular}{|c|c|c|c|c|c|c|c|c|c|}
\hline & \multirow{2}{*}{$\begin{array}{c}\text { Totals } \\
830 \\
\end{array}$} & \multicolumn{2}{|c|}{ All } & \multicolumn{2}{|c|}{ Nonwalkers } & \multicolumn{2}{|c|}{ Walkers } & \multirow{2}{*}{\multicolumn{2}{|c|}{$X^{2}(p)$}} \\
\hline & & $\mathrm{N}$ & (\%) & $\mathrm{N}=675$ & (\%) & $\mathrm{N}=155$ & (\%) & & \\
\hline \multicolumn{10}{|l|}{ Demography \& SES (Bonferroni alpha level=0.01) } \\
\hline Student gender ${ }^{\ddagger}$ & 830 & & & & & & & & \\
\hline Boy & & 412 & $(49.6)$ & 328 & $(48.6)$ & 84 & $(54.2)$ & .208 & \\
\hline Girl & & 418 & $(50.4)$ & 347 & $(51.4)$ & 71 & $(45.8)$ & & \\
\hline Student race/ethnicity ${ }^{\ddagger}$ & 826 & & & & & & & & \\
\hline Non-Hispanic Whites & & 165 & $(20.0)$ & 145 & $(21.6)$ & 20 & $(12.9)$ & .061 & \\
\hline Mexican-American Latino Hispanics & & 507 & $(61.4)$ & 399 & $(59.5)$ & 108 & $(69.7)$ & & \\
\hline African-Americans & & 53 & $(6.4)$ & 45 & $(6.7)$ & 8 & $(5.2)$ & & \\
\hline Others & & 101 & $(12.2)$ & 82 & $(12.2)$ & 19 & $(12.3)$ & & \\
\hline Does family receive any public assistance? & 777 & & & & & & & & \\
\hline No & & 244 & $(31.4)$ & 213 & $(33.6)$ & 31 & $(21.5)$ & .005 & $* *$ \\
\hline Yes & & 533 & $(68.6)$ & 420 & $(66.4)$ & 113 & $(78.0)$ & & \\
\hline Highest level of education for self? & 691 & & & & & & & & \\
\hline Up to middle school or less & & 119 & $(17.2)$ & 94 & $(16.6)$ & 25 & $(19.8)$ & .301 & \\
\hline High School or GED & & 364 & $(52.7)$ & 294 & $(52.0)$ & 70 & $(55.6)$ & & \\
\hline Associate degree to professional degree & & 208 & $(30.1)$ & 177 & $(31.3)$ & 31 & $(24.6)$ & & \\
\hline Does family own car, van or truck? & 801 & & & & & & & & \\
\hline No & & 30 & $(3.7)$ & 18 & $(2.8)$ & 12 & $(8.2)$ & .004 & ** \\
\hline Yes, one & & 326 & $(40.7)$ & 263 & $(40.2)$ & 63 & $(42.9)$ & & \\
\hline Yes, two or more & & 445 & (55.6) & 373 & $(57.0)$ & 72 & $(49.0)$ & & \\
\hline
\end{tabular}

Acculturation (Bonferroni alpha level $=0.008$ )

Language spoken most of the time by parent

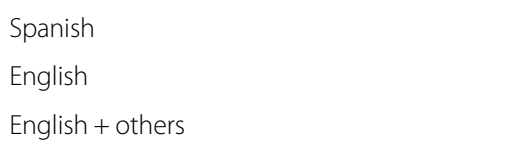

Language thought in most of the time by parent

$$
\begin{aligned}
& \text { Spanish } \\
& \text { English } \\
& \text { English + others }
\end{aligned}
$$

800

Were you born in US?

$$
\begin{aligned}
& \text { No } \\
& \text { Yes }
\end{aligned}
$$

$\begin{array}{lllllll}179 & (22.4) & 143 & (22.0) & 36 & (24.2) & .807 \\ 474 & (59.3) & 389 & (59.8) & 85 & (57.0) & \\ 147 & (18.4) & 119 & (18.3) & 28 & (18.8) & \end{array}$

Was your mother born in US?

$$
\begin{aligned}
& \text { No } \\
& \text { Yes }
\end{aligned}
$$

Was your father born in US?

$$
\begin{aligned}
& \text { No } \\
& \text { Yes }
\end{aligned}
$$

Was your child born in US?

$$
\text { No }
$$$$
\text { Yes }
$$

$\begin{array}{lcccccc}193 & (23.6) & 153 & (23.0) & 40 & (26.3) & .527 \\ 501 & (61.2) & 414 & (62.2) & 87 & (57.2) & \\ 124 & (15.2) & 99 & (14.9) & 25 & (16.4) & \end{array}$

767

$\begin{array}{lllllll}228 & (29.7) & 179 & (28.6) & 49 & (34.8) & .148 \\ 539 & (70.3) & 447 & (71.4) & 92 & (65.2) & \end{array}$

756

$\begin{array}{lllllll}326 & (43.1) & 263 & (42.7) & 63 & (45.0) & .619 \\ 430 & (56.9) & 353 & (57.3) & 77 & (55.0) & \end{array}$

$\begin{array}{lllllll}323 & (43.2) & 257 & (42.2) & 66 & (47.8) & .228 \\ 424 & (56.8) & 352 & (57.8) & 72 & (52.2) & \end{array}$

808

$\begin{array}{ccccccc}62 & (7.7) & 51 & (7.8) & 11 & (7.3) & .842 \\ 746 & (92.3) & 606 & (92.2) & 140 & (92.7) & \end{array}$


Table 2 Population characteristics and their relationships with walking to school (Continued)

Medical limitations (Bonferroni alpha level $=0.02$ )

Medical condition/disability that limit child's PA?

No

Yes

Does child have asthma?

No

If yes, is asthma well controlled by medication?

No

Yes

School policy (Bonferroni alpha level $=0.02$ )

Have teacher encouraged walk/bike to school? ${ }^{\ddagger}$

No

Yes

School has a walking school bus program $?^{\ddagger}$

No

Yes

School encourage walking/biking to/from school

Does not encourage

Encourage

Civic engagement (Bonferroni alpha level $=0.01$ )

In the past 12 months have you...

Voted in an election

797

$$
\text { No }
$$

Yes

Written/called govt. official about community issue

$$
\text { No }
$$

Yes

Attended school board, city, or other govt. meeting

$$
\text { No }
$$$$
\text { Yes }
$$

Volunteered at your child's school?

$$
\begin{aligned}
& \text { No } \\
& \text { Yes }
\end{aligned}
$$

Volunteered for any community org?

$$
\begin{aligned}
& \text { No } \\
& \text { Yes }
\end{aligned}
$$

Social Integration (Bonferroni alpha level $=0.01$ )

In my community where I live...

people work together to resolve problems

$$
\begin{aligned}
& \text { Disagree } \\
& \text { Unsure }
\end{aligned}
$$$$
\text { Agree }
$$

814

105

669

476

408

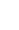

790

788

792

791

801
822

$\begin{array}{ccccccc}772 & (93.9) & 624 & (93.6) & 148 & (95.5) & .365 \\ 50 & (6.1) & 43 & (6.4) & 7 & (4.5) & \end{array}$

$\begin{array}{ccccccc}733 & (90.0) & 593 & (89.8) & 140 & (90.9) & .692 \\ 81 & (10.0) & 67 & (10.2) & 14 & (9.1) & \end{array}$

$\begin{array}{llllcll}29 & (27.6) & 27 & (30.0) & 2 & (13.3) & .181 \\ 76 & (72.4) & 63 & (70.0) & 13 & (86.7) & \end{array}$

$\begin{array}{llllllll}558 & (83.4) & 472 & (85.2) & 86 & (74.8) & .006 & * * \\ 111 & (16.6) & 82 & (14.8) & 29 & (25.2) & & \end{array}$

$\begin{array}{lllllll}349 & (73.3) & 300 & (75.0) & 49 & (64.5) & .057 \\ 127 & (26.7) & 100 & (25.0) & 27 & (35.5) & \end{array}$

$\begin{array}{lllllll}301 & (73.8) & 252 & (78.5) & 49 & (56.3) & <.001\end{array} \quad * *$

$\begin{array}{lllllll}433 & (54.3) & 341 & (52.4) & 92 & (63.0) & .020\end{array} \quad$ *

$\begin{array}{ccccccc}718 & (90.9) & 584 & (90.5) & 134 & (92.4) & .479 \\ 72 & (9.1) & 61 & (9.5) & 11 & (7.6) & \end{array}$

$\begin{array}{ccccccc}681 & (86.4) & 549 & (85.0) & 132 & (93.0) & .012 \\ 107 & (13.6) & 97 & (15.0) & 10 & (7.0) & \end{array}$

$\begin{array}{lllllll}576 & (72.7) & 461 & (71.3) & 115 & (79.3) & .049 \\ 216 & (27.3) & 186 & (28.7) & 30 & (20.7) & \text { * }\end{array}$

$\begin{array}{lllllll}584 & (73.8) & 473 & (73.2) & 111 & (76.6) & .409 \\ 207 & (26.2) & 173 & (26.8) & 34 & (23.4) & \end{array}$

$\begin{array}{lllllll}140 & (17.5) & 115 & (17.6) & 25 & (17.1) & .119 \\ 343 & (42.8) & 270 & (41.2) & 73 & (50.0) & \\ 318 & (39.7) & 270 & (41.2) & 48 & (32.9) & \end{array}$


Table 2 Population characteristics and their relationships with walking to school (Continued)

\begin{tabular}{|c|c|c|c|c|c|c|c|c|}
\hline People are only out for themselves & 800 & & & & & & & \\
\hline Disagree & & 268 & $(33.5)$ & 229 & $(34.9)$ & 39 & $(27.1)$ & .168 \\
\hline Unsure & & 327 & $(40.9)$ & 260 & $(39.6)$ & 67 & $(46.5)$ & \\
\hline A small group of people have all the power & 796 & & & & & & & \\
\hline Disagree & & 436 & $(54.8)$ & 358 & $(54.9)$ & 78 & $(54.2)$ & .831 \\
\hline Unsure & & 268 & $(33.7)$ & 217 & $(33.3)$ & 51 & (35.4) & \\
\hline Agree & & 92 & $(11.6)$ & 77 & $(11.8)$ & 15 & $(10.4)$ & \\
\hline I feel like an outsider & 787 & & & & & & & \\
\hline Disagree & & 573 & $(72.8)$ & 476 & $(73.7)$ & 97 & $(68.8)$ & .070 \\
\hline Unsure & & 145 & $(18.4)$ & 110 & $(17.0)$ & 35 & $(24.8)$ & \\
\hline Agree & & 69 & (8.8) & 60 & (9.3) & 9 & $(6.4)$ & \\
\hline Nothing I can do to solve problems that happen & 793 & & & & & & & \\
\hline Disagree & & 443 & $(55.9)$ & 369 & $(56.9)$ & 74 & $(51.4)$ & .249 \\
\hline Unsure & & 249 & $(31.4)$ & 203 & $(31.3)$ & 46 & (31.9) & \\
\hline Agree & & 101 & (12.7) & 77 & $(11.9)$ & 24 & (16.7) & \\
\hline
\end{tabular}

Texas 4th grade students, 2008-2010.

${ }^{\ddagger} Q$ Questions that were answered by the children (students). Otherwise, questions were answered by parents.

${ }^{*} \mathrm{p} \leq 0.05 ;{ }^{* *} \mathrm{p} \leq$ Bonferroni adjustment alpha level

Each personal safety variable was included in multivariable logistic regression models that adjusted for the selected confounders - student ethnicity, public assistance, and car ownership (Table 4). For home neighborhood environment, the likelihood of walking remained higher only among those who reported that it was safe for their child to walk or bike in the neighborhood. In the en-route environment, all significant associations that were observed in the unadjusted models remained after adjusting for confounders. The Hosmer-Lemeshow (H-L) tests indicated that all multivariable models fit reasonably well (data not shown).

\section{Discussion}

In this cross-sectional study, we examined the associations of parental concerns related to safety on walking to school among 4th grade students who lived within a 2mile network buffer of selected elementary schools across the state of Texas. A series of single-factor regression analyses were conducted to investigate safety concerns (road safety and personal safety) across three spatial domains (home neighborhood, en-route to school, and near the school). These analyses showed that, in general, children's walking to school depended on parental perceptions of the following factors related to road safety: sidewalks and safe road crossings in the neighborhood; sidewalks, speed and amount of traffic, and intersections along school route; and sidewalks, crossing guards, and availability of trees along streets near the school. In terms of personal safety, parents were concerned about general neighborhood safety, stray or dangerous animals, and availability of adults with whom their child can walk en-route.
Our findings expand upon prior studies that suggest that parental safety concerns are related to walking to school among children. For instance, parental perception of the presence of sidewalks was found to be associated with walking to school in all three spatial domains studied. Two prior studies using children's perspectives of the neighborhood did not find a significant association between the presence of sidewalks and walking to school $[42,43]$. Of three studies that used parent perceptions, two found a significant association $[44,45]$ while one did not [46]. The parent's perception of sidewalk availability may be more influential on children's walking to school than the perception of the child. This may be particularly true for younger children; Trapp and colleagues studied children in grades 5-7 [46], while the students in the current study were in grade 4 .

In the current study, we found more consistent associations between WTS and the road safety factors than the personal safety factors examined. The potential salience of road safety is highlighted when observed relationships with WTS are assessed in the home and school spatial domains. In the home neighborhood environment, three in four road safety items maintained significant relationships with WTS in the adjusted models, while one in four stayed significant for personal safety. A similar trend was observed for adjusted models in the school domain, with three in eight for traffic safety and zero in five for personal safety. This finding is in line with a nationally-representative study that found a greater proportion of parents felt that it was too dangerous for their 5-11 year old child to walk to school because of traffic than because of crime (37.0\% vs. $14.2 \%)$ [47], as well as a prior review on attributes of the physical environment 
Table 3 Relationships between traffic safety and walking to school

\begin{tabular}{|c|c|c|c|c|c|c|c|c|c|c|c|}
\hline \multirow{2}{*}{ Traffic safety (home) } & \multicolumn{6}{|c|}{ Unadjusted } & \multicolumn{5}{|c|}{ Adjusted $\dagger$} \\
\hline & $N=830$ & OR & \multicolumn{3}{|c|}{$95 \% \mathrm{Cl}$} & $p$ & $\mathrm{~N}=830$ & OR & \multicolumn{2}{|c|}{$95 \% \mathrm{Cl}$} & $p$ \\
\hline Sidewalks on most of neighborhood streets & 824 & & & & & & 754 & & & & \\
\hline No & & 1.00 & Ref. & & & $<.001$ & & 1.00 & Ref. & & $<.001$ \\
\hline Yes, a few & & 1.83 & 1.12 & - & 2.99 & & & 1.87 & 1.11 & 3.16 & \\
\hline Yes, many & & 2.38 & 1.53 & - & 3.71 & & & 2.69 & 1.66 & 4.35 & \\
\hline Sidewalks in neighborhood well maintained & 700 & & & & & & 634 & & & & \\
\hline No & & 1.00 & Ref. & & & .029 & & 1.00 & Ref. & & .005 \\
\hline Yes, a few & & 1.47 & 0.90 & - & 2.39 & & & 1.68 & 0.99 & 2.86 & \\
\hline Yes, many & & 1.88 & 1.17 & - & 3.02 & & & 2.20 & 1.30 & 3.71 & \\
\hline Safe road crossings in your neighborhood & 774 & & & & & & 708 & & & & \\
\hline No & & 1.00 & Ref. & & & .001 & & 1.00 & Ref. & & $<.001$ \\
\hline Yes, a few & & 1.84 & 1.16 & - & 2.91 & & & 1.95 & 1.19 & 3.19 & \\
\hline Yes, many & & 2.50 & 1.51 & - & 4.13 & & & 2.61 & 1.51 & 4.49 & \\
\hline People walk/bike in your neighborhood & 812 & & & & & & 743 & & & & \\
\hline No & & 1.00 & Ref. & & & .356 & & 1.00 & Ref. & & .001 \\
\hline Yes, a few & & 1.35 & 0.66 & - & 2.74 & & & 1.45 & 0.68 & 3.08 & \\
\hline Yes, many & & 1.62 & 0.78 & - & 3.35 & & & 1.82 & 0.83 & 4.00 & \\
\hline \multicolumn{12}{|l|}{ Traffic safety (en-route) } \\
\hline Always a problem & & 1.00 & Ref. & & & $<.001$ & & 1.00 & Ref. & & $<.001$ \\
\hline Sometimes a problem & & 1.68 & 0.99 & - & 2.83 & & & 1.84 & 1.03 & 3.28 & \\
\hline Not a problem & & 2.69 & 1.64 & - & 4.42 & & & 2.86 & 1.64 & 4.99 & \\
\hline Amount of traffic along route a problem & 800 & & & & & & 732 & & & & \\
\hline Always a problem & & 1.00 & Ref. & & & $<.001$ & & 1.00 & Ref. & & $<.001$ \\
\hline Sometimes a problem & & 2.40 & 1.41 & - & 4.11 & & & 2.72 & 1.51 & 4.87 & \\
\hline Not a problem & & 3.66 & 2.17 & - & 6.17 & & & 3.87 & 2.19 & 6.86 & \\
\hline Sidewalks or pathways a problem & 795 & & & & & & 728 & & & & \\
\hline Always a problem & & 1.00 & Ref. & & & $<.001$ & & 1.00 & Ref. & & $<.001$ \\
\hline Sometimes a problem & & 1.58 & 0.85 & - & 2.95 & & & 1.62 & 0.84 & 3.12 & \\
\hline Not a problem & & 3.35 & 1.99 & - & 5.66 & & & 3.38 & 1.94 & 5.89 & \\
\hline Safety at intersections $\&$ crossings a problem & 801 & & & & & & 736 & & & & \\
\hline Always a problem & & 1.00 & Ref. & & & $<.001$ & & 1.00 & Ref. & & $<.001$ \\
\hline Sometimes a problem & & 2.89 & 1.52 & - & 5.49 & & & 2.65 & 1.37 & 5.11 & \\
\hline Not a problem & & 5.27 & 2.85 & - & 9.74 & & & 4.75 & 2.54 & 8.89 & \\
\hline Crossing guards a problem & 792 & & & & & & 727 & & & & \\
\hline Always a problem & & 1.00 & Ref. & & & $<.001$ & & 1.00 & Ref. & & $<.001$ \\
\hline Sometimes a problem & & 2.58 & 1.13 & - & 5.87 & & & 2.41 & 1.04 & 5.62 & \\
\hline Not a problem & & 5.17 & 2.45 & - & 10.89 & & & 4.90 & 2.29 & 10.46 & \\
\hline \multicolumn{12}{|l|}{ Traffic safety (school) } \\
\hline Sidewalks on streets near child's school & 814 & & & & & & 745 & & & & \\
\hline No & & 1.00 & Ref. & & & .003 & & 1.00 & Ref. & & $<.001$ \\
\hline Yes, a few & & 1.84 & 1.07 & - & 3.16 & & & 2.05 & 1.14 & 3.67 & \\
\hline Yes, many & & 2.41 & 1.41 & - & 4.10 & & & 3.07 & 1.71 & 5.50 & \\
\hline
\end{tabular}


Table 3 Relationships between traffic safety and walking to school (Continued)

\begin{tabular}{|c|c|c|c|c|c|c|c|c|c|c|c|}
\hline Sidewalks well maintained & 736 & & & & & & 670 & & & & \\
\hline No & & 1.00 & Ref. & & & .086 & & 1.00 & Ref. & & $<.001$ \\
\hline Yes, a few & & 0.89 & 0.52 & - & 1.52 & & & 1.17 & 0.65 & 2.09 & \\
\hline Yes, many & & 1.39 & 0.83 & - & 2.34 & & & 1.88 & 1.06 & 3.35 & \\
\hline Trees along streets near school & 796 & & & & & & 727 & & & & \\
\hline No & & 1.00 & Ref. & & & .201 & & 1.00 & Ref. & & .001 \\
\hline Yes, a few & & 1.52 & 0.90 & - & 2.56 & & & 1.80 & 1.02 & 3.17 & \\
\hline Yes, many & & 1.60 & 0.91 & - & 2.79 & & & 2.07 & 1.12 & 3.82 & \\
\hline Bike lanes/paths or trails near school & 788 & & & & & & 719 & & & & \\
\hline No & & 1.00 & Ref. & & & .061 & & 1.00 & Ref. & & $<.001$ \\
\hline Yes, a few & & 1.56 & 1.04 & - & 2.36 & & & 1.75 & 1.13 & 2.70 & \\
\hline Yes, many & & 1.59 & 0.87 & - & 2.91 & & & 1.46 & 0.74 & 2.86 & \\
\hline Bike lanes/paths or trails well maintained & 563 & & & & & & 510 & & & & \\
\hline No & & 1.00 & Ref. & & & .541 & & 1.00 & Ref. & & .044 \\
\hline Yes, a few & & 1.20 & 0.75 & - & 1.92 & & & 1.32 & 0.80 & 2.17 & \\
\hline Yes, many & & 1.34 & 0.76 & - & 2.37 & & & 1.43 & 0.76 & 2.68 & \\
\hline Bike racks at or near school & 763 & & & & & & 699 & & & & \\
\hline No & & 1.00 & Ref. & & & .662 & & 1.00 & Ref. & & .004 \\
\hline Yes, a few & & 1.16 & 0.77 & - & 1.74 & & & 1.38 & 0.89 & 2.14 & \\
\hline Yes, many & & 1.28 & 0.70 & - & 2.33 & & & 1.40 & 0.72 & 2.72 & \\
\hline Safe road crossings & 802 & & & & & & 734 & & & & \\
\hline No & & 1.00 & Ref. & & & .047 & & 1.00 & Ref. & & $<.001$ \\
\hline Yes, a few & & 1.86 & 1.11 & - & 3.13 & & & 2.15 & 1.22 & 3.78 & \\
\hline Yes, many & & 1.56 & 0.85 & - & 2.85 & & & 2.06 & 1.06 & 4.00 & \\
\hline
\end{tabular}

Regression Analyses - (Unadjusted and Adjusted Odds Ratios): Texas 4th grade students, 2008-2010.

${ }^{\dagger}$ Adjusted for: Socio-demographic - student's ethnicity, any type of public assistance (family), car ownership (family).

Boldface type indicates there was a significant difference with the reference group at 95 percent confidence interval in the adjusted model.

and children's physical activity levels [48] [37]. In this review, parental concerns about road hazards (street crossings and traffic) were more consistently associated with children's physical activity levels than were perceptions of safety from crime.

Our findings suggest that the en-route environment may be the most critical environment to parents for both traffic safety and personal safety. All but one of the 8 items that were assessed in the en-route environment maintained significant relationships with walking to school in the expected direction, i.e. more safety concern associated with less walking to school. Comparatively, 4 of 8 and 3 of 13 items remained significant in adjusted models at the home neighborhood and school environment respectively. Further, the largest measures of effect were seen in the en-route domain. These findings suggest that parents may weigh the safety of the specific route a child will travel over the safety of the neighborhood or school environment when deciding whether to allow their child to walk to school. This finding lends further support to the call for specificity when defining the spatial domain of a behavior of interest [49].
Our assessment of the relationships between the selected covariates and WTS confirmed previous findings in some cases, and offered some additional insights. We saw a negative relationship between indicators of socioeconomic status and walking to school, as has been generally, but not consistently, noted in other studies. A 2009 systematic review of determinants of children's active travel reported negative associations with children's active travel in six of seven studies that considered household income, nine of twelve studies considering car ownership, and four of twelve that considered parental education [24]. We also found that student perception of teacher support and parent perception of school support for active commuting had a positive association with students' walking to school. A similar finding has been reported in at least one prior study [46]. Considering the low prevalence of this perception among students (16.6\%) and parents $(26.2 \%)$ in this study, school policy may be a practical target for interventions. For instance, schools may consider adopting an official policy statement to support active commuting to school and making this statement of 
Table 4 Relationships between personal safety and walking to school

Personal safety (home)
Do you feel safe walking in neighborhood ${ }^{\ddagger}$
Never
Some of the time
Most/all of the time
Do you feel safe riding a bike in neighborhood ${ }^{\ddagger}$
Never
Some of the time
Most/all of the time

Safe for child to walk/bike in neighborhood

Never/not very often

Some of the time

Most/all of the time

Afraid when out alone after dark in community

$$
\begin{aligned}
& \text { Disagree } \\
& \text { Unsure }
\end{aligned}
$$

Agree

\section{Personal Safety (En-route)}

Adults, other children to walk/bike with

$$
\begin{aligned}
& \text { Not a problem } \\
& \text { Sometimes a problem } \\
& \text { Always a problem }
\end{aligned}
$$

Violence or crime a problem

$$
\begin{aligned}
& \text { Not a problem } \\
& \text { Sometimes a problem } \\
& \text { Always a problem }
\end{aligned}
$$

Stray or dangerous animals a problem

$$
\text { Not a problem }
$$

Sometimes a problem

Always a problem

Personal safety (school)

Near child's school...

Attractive buildings and natural things to see

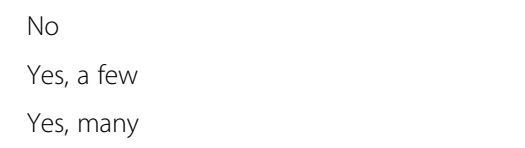

Abandoned houses or vacant lots

$$
\begin{aligned}
& \text { No } \\
& \text { Yes, a few } \\
& \text { Yes, many }
\end{aligned}
$$

$$
\begin{array}{lllll}
819 & 1.00 & \text { Ref. } & \\
& 0.86 & 0.59 & - & 1.25 \\
& 1.02 & 0.52 & - & 2.01 \\
& & & & \\
& & & & \\
& & & \\
& 1.00 & \text { Ref. } & & \\
& 1.06 & 0.74 & - & 1.53 \\
& 1.02 & 0.49 & - & 2.12
\end{array}
$$$$
.947
$$$$
752
$$$$
1.00 \text { Ref. }
$$$$
1.030 .69-1.51
$$$$
0.690 .29-1.63
$$

741

1.00 Ref. $\quad .704$

$$
\begin{array}{lll}
1.00 & \text { Ref. } & \\
1.23 & 0.66 & - \\
& & \\
1.29
\end{array}
$$$$
\begin{array}{lll}
1.42 & 0.82 & -
\end{array}
$$$$
756
$$

$$
\begin{array}{lll}
1.00 & \text { Ref. } & \\
0.90 & 0.49- & 1.67
\end{array}
$$$$
0.98 \quad 0.58-1.64
$$

737

$$
\begin{array}{lll}
1.00 & \text { Ref. } & \\
1.61 & 0.95 & -
\end{array}
$$$$
\begin{array}{llll}
2.42 & 1.47 & - & 3.99
\end{array}
$$

730

$$
\begin{aligned}
& 1.00 \text { Ref. } \\
& \begin{array}{lll}
0.78 & 0.45 & -
\end{array} .32 \\
& \begin{array}{lll}
1.03 & 0.67-1.60
\end{array}
\end{aligned}
$$

4

$p$

Condoms, drug-related paraphernalia (needles, syringes, etc.)

$\begin{array}{lllllll}0.001 & & & & & \\ 0.40 & 0.26 & - & 0.62 & \mathbf{0 . 4 2} & \mathbf{0 . 2 7} & -\mathbf{0 . 6 6} \\ 0.75 & 0.39 & -1.46 & 0.69 & 0.34 & - & 1.39\end{array}$

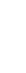

.003

1


Table 4 Relationships between personal safety and walking to school (Continued)

\begin{tabular}{|c|c|c|c|c|c|c|c|c|c|c|c|c|}
\hline Yes, a few & & 0.73 & 0.32 & - & 1.65 & & & 0.88 & 0.38 & - & 2.06 & \\
\hline Yes, many & & 1.25 & 0.26 & - & 6.07 & & & 1.63 & 0.32 & - & 8.33 & \\
\hline Well-maintained homes, apartments \& gardens & 817 & & & & & & 748 & & & & & \\
\hline No & & 1.00 & Ref. & & & .799 & & 1.00 & Ref. & & & .005 \\
\hline Yes, a few & & 0.82 & 0.43 & - & 1.55 & & & 0.88 & 0.44 & - & 1.75 & \\
\hline Yes, many & & 0.80 & 0.41 & - & 1.54 & & & 0.97 & 0.47 & - & 1.99 & \\
\hline
\end{tabular}

Regression Analyses - (Crude and Adjusted Odds Ratios): Texas 4th grade students, 2008-2010.

${ }^{\dagger}$ Adjusted for: Socio-demographic - student's ethnicity, any type of public assistance (family), car ownership (family).

¥Questions that were answered by the children (students). Otherwise, questions were answered by parents.

Boldface type indicates there was a significant difference with the reference group at 95 percent confidence interval in the adjusted model.

support known to all families and the larger community. Also, we saw negative associations between several measures of civic engagement (voted in an election, attended a school board meeting, and volunteered in child's school) and WTS, significant at the $\mathrm{p}<0.05$ level, although these were not significant with the Bonferroni correction. Taken together, these results suggest that children from higher SES families and those who are civically-engaged may be less likely to walk to school than their counterparts. Any relationships between these variables are likely complex, but do suggest that social norms may be involved. Further work in this area may be warranted.

Several potential limitations can be noted. The crosssectional design precludes causal inference, and our findings were based on self-reported information, which may lead to recall bias. Respondent burden might have played some role in the general response rate of the parents (31.6\%), and possibly influenced the reliability of reported study variables. However, other researchers and governmental organizations rely on self-reported information for their analyses, and evidence of a systematic bias due to self-reporting of mode choice to school is largely absent in the literature. Importantly, given that perceived safety was the primary exposure of interest in the current set of analyses, the use of survey was therefore an appropriate means of measuring participants' perceptions. Another issue that is related to the assessment of perceived safety concerns and WTS is the potential for a mismatch between perceptions of safety and "actual safety". Others have reported differing findings on the concordance between environmental perceptions and objective measures [50-52]. Therefore, if safety perceptions do not correspond well to actual risk in the home-to-school journey, attempts to improve traffic or personal safety "on the ground" might not increase WTS. Essentially, it may be that it is the perceptions of risk that need changing as much, or even more, than the actual environment. This point is being highlighted in the current paper, as an important theme in this subfield. Nonetheless, an in-depth critique is beyond the scope of the current study.

Despite the acknowledged limitations, our findings have relevance to the behavioral medicine field in a variety of ways. First of all, the current study asked participants about specific safety concerns, rather than using general safety questions, which provides evidence that road safety may be more relevant than personal safety to parents, as far as walking to school is concerned. However, despite this more robust assessment, the full range of parental perceptions around safety for their child may not be fully captured. Future research would benefit from the use of qualitative data gathering in communities (e.g. focus group discussions and interviews) to improve the operationalization of safety concern constructs. Secondly, a major contribution to existing knowledge is the level of spatial specificity offered by T-COPPE data that previous studies have lacked. This study provides the ability to examine relevant safety concerns across different spatial domains (i.e., home neighborhood, en-route, and school environments) going beyond previous single domain studies. Consequently, we were able to examine the differential effects in the exposure-outcome relationships across these spatially-distinct domains.

There are other prominent aspects of the T-COPPE study. T-COPPE participants were selected from both urban and rural schools across Texas; therefore, our findings may be generally applicable to Texas 4th grade students and their parents. Notably, since the current analyses included participants that live within a 2-mile distance from their school, this inclusion criterion addressed potential rural-urban distance-based differences. The TCOPPE population was more diverse and low income than previously reported data, and our sample is fairly large when compared to other similar studies. The methods used for construct development, data sourcing, and analyses can be replicated in most, if not all, settings.

\section{Conclusions}

Results indicate that specific safety concerns in the neighborhood socio-environmental characteristics explained some of the variance in walking to school among 4th grade students in the present study. Of particular importance to parents is traffic safety along the route to the school. Based on these findings, we expect that increased focus on, and investment in, pedestrian- 
centric transportation infrastructures would result in increased WTS. In environments where active commuting to school has adequate infrastructure support, school encouragement of active commuting is recommended. In addition to enabling overall physical activity in children, such investments could result in a longterm population-wide health benefit, affecting all the people in the target neighborhoods.

\section{Competing interests}

The authors declare that they have no competing interests.

\section{Authors' contributions}

AOO conceptualized and designed the study, assembled and processed the data for current analyses, oversaw the data analyses and the interpretations of findings, and led the overall writing of the article. $\mathrm{CL}$ conceptualized and designed the study, assembled and processed the data for current analyses, contributed to data analyses and interpretations, contributed to the drafting of the article. EKN was involved in data analyses and interpretations and contributed to the drafting of the article. DD, MO, and $\mathrm{DMH}$ supervised the data collection, access sharing and management for the parent study (T-COPPE) and contributed equally to the interpretation of findings. All authors edited drafts of the article for important intellectual content. All authors read and approved the final manuscript.

\section{Acknowledgements}

This study was funded by the Robert Wood Johnson Foundation (Grant ID: 64635) and contributions from The University of Texas School of Public Health, the Texas A\&M Health Science Center (TAMHSC) School of Rural Public Health, Texas Health Institute, and Live Smart Texas. Dr. Oluyomi is supported by the Michael \& Susan Dell Foundation and the National Institutes of Health (NIH Grant/Award: 5K07CA126988-05). We would like to thank Carolyn Smith and Heather Atteberry for their diligence with recruitment of participants for the T-COPPE project and survey administration. We thank Suojin Wang, Jingang Miao, and Young-Jae Kim for their support in the preparation of the T-COPPE data sets for analyses. We acknowledge the work of other individuals that are involved in the overall management of the T-COPPE project, both at the UTSPH and TAMHSC.

\section{Author details}

'The Michael \& Susan Dell Center for Healthy Living, UT School of Public Health, Austin Regional Campus, The University of Texas Health Science Center at Houston, 1616 Guadalupe, Suite 6.300, Austin, TX 78701, USA. ${ }^{2}$ Department of Landscape Architecture and Urban Planning, College of Architecture, Texas A\&M University, W014D Williams Administration Building, College Station, TX 77843-3137, USA. ${ }^{3}$ School of Rural Public Health, Texas A\&M Health Science Center, SRPH Administration Building, College Station, TX 77843-1266, USA.

Received: 14 April 2013 Accepted: 26 February 2014

Published: 6 March 2014

\section{References}

1. Dollman J, Norton K, Norton L: Evidence for secular trends in children's physical activity behaviour. Br J Sports Med 2005, 39:892-897.

2. Nelson MC, Neumark-Stzainer D, Hannan PJ, Sirard JR, Story M: Longitudinal and secular trends in physical activity and sedentary behavior during adolescence. Pediatrics 2006, 118:e1627-e1634.

3. Janssen I, LeBlanc AG: Systematic review of the health benefits of physical activity and fitness in school-aged children and youth. Int J Behav Nutr Phys Act 2010, 7:40.

4. Strong WB, Malina RM, Blimkie CJ, Daniels SR, Dishman RK, Gutin B, Hergenroeder AC, Must A, Nixon PA, Pivarnik JM: Evidence based physical activity for school-age youth. J Pediatr 2005, 146:732-737.

5. Cooper AR, Andersen LB, Wedderkopp N, Page AS, Froberg K: Physical activity levels of children who walk, cycle, or are driven to school. Am J Prev Med 2005, 29:179-184.
6. Heelan KA, Donnelly JE, Jacobsen DJ, Mayo MS, Washburn R, Greene L: Active commuting to and from school and BMI in elementary school children-preliminary data. Child Care Health Dev 2005, 31:341-349.

7. Saksvig BI, Catellier DJ, Pfeiffer K, Schmitz KH, Conway T, Going S, Ward D, Strikmiller P, Treuth MS: Travel by walking before and after school and physical activity among adolescent girls. Arch Pediatr Adolesc Med 2007, 161:153.

8. Southward EF, Page AS, Wheeler BW, Cooper AR: Contribution of the school journey to daily physical activity in children aged 11-12 years. Am J Prev Med 2012, 43:201-204.

9. Cooper AR, Page AS, Foster LJ, Qahwaji D: Commuting to school: are children who walk more physically active? Am J Prev Med 2003, 25:273-276.

10. Goodman A, Mackett RL, Paskins J: Activity compensation and activity synergy in British 8-13 year olds. Prev Med 2011, 53:293-298.

11. Dollman J, Lewis NR: Active transport to school as part of a broader habit of walking and cycling among South Australian youth. Pediatr Exerc Sci 2007, 19:436.

12. McDonald NC, Brown AL, Marchetti LM, Pedroso MS: US school travel, 2009: an assessment of trends. Am J Prev Med 2011, 41:146-151.

13. Martin S, Carlson S: Barriers to children walking to or from school: United States. Morb Mortal Wkly Rep 2004, 2005:54.

14. Beck LF, Greenspan Al: Why don't more children walk to school? J Safety Res 2008, 39(5):449-452.

15. Ham SA, Martin S, Kohl H III: Changes in the percentage of students who walk or bike to school-United States, 1969 and 2001. J Phys Act 2008, 5:205.

16. McDonald NC: Children's mode choice for the school trip: the role of distance and school location in walking to school. Transportation 2008, 35:23-35.

17. Yarlagadda AK, Srinivasan S: Modeling children's school travel mode and parental escort decisions. Transportation 2008, 35:201-218.

18. Zhu X, Lee C: Correlates of walking to school and implications for public policies: survey results from parents of elementary school children in Austin, Texas. J Public Health Policy 2009:S177-S202.

19. Alton $D, A d a b P$, Roberts $L$, Barrett $T$ : Relationship between walking levels and perceptions of the local neighbourhood environment. Arch Dis Child 2007, 92:29-33.

20. Salmon J, Salmon L, Crawford DA, Hume C, Timperio A: Associations among individual, social, and environmental barriers and children's walking or cycling to school. Am J Health Promot 2007, 22:107-113.

21. Timperio A, Crawford D, Telford A, Salmon J: Perceptions about the local neighborhood and walking and cycling among children. Prev Med 2004, 38:39-47.

22. Lee C, Zhu X, Yoon J, Varni JW: Beyond distance: children's school travel mode choice. Ann Behav Med 2013, 45:55-67.

23. Davison KK, Werder JL, Lawson CT: Peer reviewed: children's active commuting to school: current knowledge and future directions. Prev Chronic Dis [serial online] 2008, 5:A100.

24. Pont K, Ziviani J, Wadley D, Bennett S, Abbott R: Environmental correlates of children's active transportation: a systematic literature review. Health Place 2009, 15:849-862.

25. The State of Texas: Texas Education Code. Section No. 42.155(b) (1). Accessible at: http://www.statutes.legis.state.tx.us/Docs/ED/htm/ED.42.htm.

26. National Center for Safe Route to School: National Center for Safe Route To School Evaluation: Parent Survey. Accessible at: http://www. saferoutesinfo.org/program-tools/evaluation-parent-survey.

27. Braza M, Shoemaker W, Seeley A: Neighborhood design and rates of walking and biking to elementary school in 34 California communities. Am J Health Promot 2004, 19:128-136.

28. Evenson KR, Huston SL, McMillen BJ, Bors P, Ward DS: Statewide prevalence and correlates of walking and bicycling to school. Arch Pediatr Adolesc Med 2003, 157:887.

29. Harten N, Olds T: Patterns of active transport in 11-12 year old Australian children. Aust N Z J Public Health 2004, 28:167.

30. Hoelscher DM, Day RS, Lee ES, Frankowski RF, Kelder SH, Ward JL, Scheurer ME: Measuring the prevalence of overweight in Texas schoolchildren. Am J Public Health 2004, 94:1002.

31. Olvera N, Lee C, Smith D: Urban Hispanic Perception of Environment and Activity among Kids (UHPEAK) study. In Progress Report 2010. Submitted to the Robert Wood Johnson Foundation.

32. Cerin E, Saelens BE, Sallis JF, Frank LD: Neighborhood environment walkability scale: validity and development of a short form. Med Sci Sports Exerc 2006, 38:1682. 
33. Saelens BE, Sallis JF, Black JB, Chen D: Neighborhood-based differences in physical activity: an environment scale evaluation. Am J Public Health 2003, 93:1552-1558,

34. Springer AE, Kelder SH, Barroso CS, Drenner KL, Shegog R, Ranjit N, Hoelscher DM: Parental influences on television watching among children living on the Texas-Mexico border. Prev Med 2010, 51:112-117.

35. Narayan D, Cassidy MF: A dimensional approach to measuring social capital: development and validation of a social capital inventory. Curr Sociol 2001, 49:59-102.

36. Wendel ML: Social capital and health: individual measures, community influences, and persistent questions [doctoral]. In College Station, TX: Social and Behavioral Health. Texas: A\&M Health Science Center School of Rural Public Health; 2009,

37. Brownson RC, Chang JJ, Eyler AA, Ainsworth BE, Kirtland KA, Saelens BE, Sallis JF: Measuring the environment for friendliness toward physical activity: a comparison of the reliability of 3 questionnaires. Am J Public Health 2004, 94:473.

38. Sallis JF, Taylor W, Dowda M, Freedson P, Pate R: Correlates of vigorous physical activity for children in grades 1 through 12: comparing parent-reported and objectively measured physical activity. Pediatr Exerc Sci 2002, 14:30-44.

39. Trost SG, Sallis JF, Pate RR, Freedson PS, Taylor WC, Dowda M: Evaluating a model of parental influence on youth physical activity. Am J Prev Med 2003, 25:277-282.

40. Currie C, Molcho M, Boyce W, Holstein B, Torsheim T, Richter M: Researching health inequalities in adolescents: the development of the Health Behaviour in School-Aged Children (HBSC) family affluence scale. Soc Sci Med 2008, 66:1429-1436.

41. Mier N, Smith ML, Carrillo-Zuniga G, Wang X, Garza N, Ory MG: Personal and cultural influences on diabetes self-care behaviors among older Hispanics born in the us and Mexico. J Immigr Minor 2012:1-11.

42. Davison KK, Lawson CT: Do attributes in the physical environment influence children's physical activity? A review of the literature. Int J Behav Nutr Phys Act 2006, 3:19.

43. Evenson KR, Birnbaum AS, Bedimo-Rung AL, Sallis JF, Voorhees CC, Ring K, Elder JP: Girls' perception of physical environmental factors and transportation: reliability and association with physical activity and active transport to school. Int I Behav Nutr Phys Act 2006, 3:28.

44. Fulton JE, Shisler JL, Yore MM, Caspersen CJ: Active transportation to school: findings from a national survey. Res Q Exerc 2005, 76:352-357.

45. Mota J, Gomes H, Almeida M, Ribeiro JC, Carvalho J, Santos MP: Active versus passive transportation to school-differences in screen time, socio-economic position and perceived environmental characteristics in adolescent girls. Ann Hum Biol 2007, 34:273-282.

46. Trapp GS, Giles-Corti B, Christian HE, Bulsara M, Timperio AF, McCormack GR, Villaneuva KP: Increasing children's physical activity individual, social, and environmental factors associated with walking to and from school. Health Educ Behav 2012, 39:172-182.

47. Cho CM, Choi YS: The effect of resident-perceived neighborhood boundary on the equity of public parks distribution: using GIS. Web and Wireless Geographical Information Systems 2005:296-307.

48. MMWR: Barriers to children walking to or from school-United States, 2004. Morb Mortal Wkly Rep 2005, 54:949-952.

49. Giles-Corti B, Timperio A, Bull F, Pikora T: Understanding physical activity environmental correlates: increased specificity for ecological models. Exerc Sport Sci Rev 2005, 33:175.

50. Ball K, Jeffery RW, Crawford DA, Roberts RJ, Salmon J, Timperio AF: Mismatch between perceived and objective measures of physical activity environments. Prev Med 2008, 47:294-298.

51. Gebel K, Bauman A, Owen N: Correlates of non-concordance between perceived and objective measures of walkability. Ann Behav Med 2009, 37:228-238.

52. Prins R, Oenema A, van der Horst $K$, Brug J: Objective and perceived availability of physical activity opportunities: differences in associations with physical activity behavior among urban adolescents. Int I Behav Nutr Phys Act 2009, 6:70.

doi:10.1186/1479-5868-11-32

Cite this article as: Oluyomi et al:: Parental safety concerns and active school commute: correlates across multiple domains in the home-to-school journey. International Journal of Behavioral Nutrition and Physical Activity 2014 11:32.

\section{Submit your next manuscript to BioMed Central and take full advantage of:}

- Convenient online submission

- Thorough peer review

- No space constraints or color figure charges

- Immediate publication on acceptance

- Inclusion in PubMed, CAS, Scopus and Google Scholar

- Research which is freely available for redistribution 